\title{
La Reconquista islámica: \\ el orientalismo de Miguel Asín Palacios \\ y la participación de marroquíes \\ en la Guerra Civil española
}

\author{
PABLo BORNSTEIN \\ Universidad de Tel Aviv (Israel) \\ orcid.org/0000-0003-0972-9087
}

Presentación: 31 dic. 2019 | Aceptación: 3 abril 2020 | Publicación: 31 oct. 2020

Cita recomendada: Bornstein, Pablo. 2020. «La Reconquista islámica: el orientalismo de Miguel Asín Palacios y la participación de marroquies en la Guerra Civil española». Dictatorships \& Democracies. Journal of History and Culture 8: 159-185. doi: https://dx.doi.org/10.7238/dd.voi8.3182

Resumen: El artículo examina el discurso franquista en torno a la presencia de marroquíes musulmanes en el Ejército nacional durante la Guerra Civil española, analizando cómo la justifica el arabista Miguel Asín Palacios (1871-1944). Además, vincula dicha justificación, hecha durante la posguerra, con la trayectoria académica anterior a la guerra de Asín Palacios. Sostiene, finalmente, que la argumentación de Asín Palacios sobre las motivaciones de las tropas marroquíes para luchar en España es inseparable de la interpretación histórica que el propio arabista aragonés había desarrollado durante varias décadas, en relación con el estudio de los préstamos culturales entre el mundo islámico y el mundo cristiano durante la edad media. La particular visión de Asín Palacios sobre la existencia de afinidades teológicas profundas entre el islam y el catolicismo permitió a la propaganda franquista justificar la presencia de tropas musulmanes en la guerra en función de una idea de cruzada religiosa supuestamente compartida por ambas confesiones, en lucha contra el materialismo ateo de las fuerzas republicanas.

Palabras clave: orientalismo, Guerra civil española, franquismo, colonialismo, protectorado español de Marruecos

The Islamic Reconquista: the Orientalism of Miguel Asín Palacios and the Moroccan Involvement in the Spanish Civil War

Abstract: This paper analyzes the Francoist discourse regarding the presence of Muslim Moroccan troops in the Nationalist Army during the Spanish Civil War, attending to how it was justified by Arabist scholar Miguel Asín Palacios (1871-1944). It also posits that Asín Palacios' postwar justification was conceived against the backdrop of his earlier academic works, and argues that the rationale behind his thesis connected with his peculiar interpretation of the history of cultural transferences between the Muslim and the Christian worlds during the Iberian Middle Ages. Asín Palacios' particular understanding of the theological affinities between Islam and Catholicism helped 
Francoist propaganda in portraying the participation of Muslim troops in the Spanish Civil War as stemming from a joint religious crusade against the materialist, godless forces of the Spanish Republic.

Keywords: Orientalism, Spanish Civil War, Francoist regime, colonialism, Spanish protectorate in Morocco

La masiva presencia de soldados marroquíes de confesión islámica en el conflicto que asoló España entre 1936 y 1939, bajo el mando de unas autoridades militares que luchaban al amparo de la Iglesia católica, y que definían su empresa bélica como una cruzada, no deja de producir cierta extrañeza a día de hoy. ${ }^{1}$ La propaganda franquista, tanto durante la propia contienda como en los años posteriores, invirtió grandes esfuerzos en intentar despejar la aparente contradicción que esto suponía. El alto mando franquista contaba con una abrumadora presencia de generales africanistas que habían desarrollado buena parte de su carrera militar en el protectorado español de Marruecos, combatiendo la resistencia anticolonial de las tribus locales. A pesar de que la visión que esta oficialidad africanista tenía sobre los nativos marroquíes fue construida en gran medida sobre la base de estereotipos racistas muy arraigados en el imaginario colectivo español, la incorporación de tropas nativas en el Ejército colonial, y el apoyo de ciertos notables indígenas a la acción militar española en el protectorado, favorecieron la consolidación de una imagen más positiva de los nativos, vinculada a la figura del «moro amigo», que, sin embargo, se mantendría en constante tensión con los fuertemente arraigados prejuicios negativos (Velasco de Castro 2014).

La incorporación del «moro amigo» en la cruzada desplegada a partir de julio de 1936 iba a exigir en cualquier caso una reelaboración discursiva especialmente compleja. La noción religiosa implícita en la concep-

1 Existe una importante bibliografía en torno a la participación de tropas marroquíes en la Guerra Civil española. Pueden consultarse, entre otros, Madariaga (2006), Mesa (2004), García Cruz (2002), López Barranco (2006) y Wright (2020). Un panorama general sobre esta producción historiográfica, en el que se plantea el estado de la cuestión en torno a diversas problemáticas, tales como la cuantificación del número total de combatientes marroquíes o el tratamiento que se ha dado al estudio de las motivaciones de los marroquíes para combatir en la contienda, lo podemos encontrar en Mechbal (2011). 
ción franquista de «cruzada» no iba a ser elaborada ya como una lucha entre distintas confesiones, sino que iba a quedar definida como un enfrentamiento sin cuartel entre el idealismo religioso de la auténtica España, fiel a su tradición católica, y entre un materialismo que presuntamente llevaba siglos minando la espiritualidad de la nación española, y que encontraba en el marxismo con el que supuestamente había quedado infectada la España republicana su más atroz encarnación. En esa conflagración, la España verdadera encontraría un improbable aliado en el mundo musulmán, en el que repentinamente se descubría una sensibilidad religiosa cercana a la española.

Con el objetivo de facilitar este giro discursivo, la propaganda franquista se apoyaría sobre la producción académica del orientalismo español, y, de hecho, iba a encontrar en Miguel Asín Palacios (1871-1944), uno sus más destacados representantes, a un inestimable colaborador. En 1940 Asín Palacios publicaba en el Boletín de la Universidad Central de Madrid un artículo titulado «Por qué lucharon a nuestro lado los musulmanes marroquíes», sin duda alguna la más elaborada justificación teórica del bando franquista sobre la presencia de las tropas moras en la llamada cruzada nacional. En nuestro análisis subrayamos la estrecha relación que existe entre algunas de las problemáticas planteadas por el arabismo español en las primeras décadas del siglo xx y los argumentos usados por Asín a la hora de explicar «uno de los espectáculos que más viva sorpresa produjo [la Guerra Civil] en el ánimo del observador medianamente curioso» (Asín 1948, 127). En esas décadas, Asín se erigió de forma indiscutible como la principal figura del arabismo español, gracias a una serie de estudios de marcado carácter esencialista en los que se valoraba, desde una perspectiva inédita, la profundidad telúrica de las transferencias culturales entre el islam y el cristianismo en la España medieval. Se hace necesario atender a ese recorrido historiográfico para poder comprender en todo su sentido la manera en la que Asín llegó a concebir la insólita presencia de tropas musulmanas en la «reconquista de la España sovietizada» protagonizada por el Ejército franquista (Asín 1948, 127).

Tras trazar un breve esbozo sobre el desarrollo del orientalismo español moderno, analizaremos la justificación que usa Asín Palacios para explicar la presencia de tropas marroquíes en el Ejército franquista a la 
luz de la propia evolución de su obra académica y de su trayectoria como arabista. En la parte final de este artículo consideramos el peso que tuvo la heurística historiográfica del arabista aragonés en la formulación del ideario del primer franquismo respecto al mundo islámico. Un aspecto que se detecta a simple vista tras una primera lectura del artículo de Asín sobre las tropas marroquíes es su evidente falta de detalle acerca de las condiciones, tanto sociológicas como económicas, bajo las que se produjeron los reclutamientos. Esto se percibe de forma aún más clara al contrastar la situación dibujada por el arabista aragonés con la realidad que se desprende de las investigaciones históricas más recientes en torno a la experiencia de las tropas marroquíes en el Ejército franquista. La interpretación hecha por Asín aparecía, así, como el corolario de unos planteamientos teóricos elaborados durante décadas por una historiografía orientalista obnubilada por el deseo de revelar el carácter español de la cultura andalusí. Respondía de esta forma a las necesidades de un discurso nacionalista devenido ahora en legitimación intelectual de la nueva España franquista, y no a un esfuerzo por analizar las consecuencias empíricas de la dominación colonial española sobre el norte de Marruecos. Este artículo se centra, por tanto, en la producción académica de ese orientalismo, en el que Asín destacó sin lugar a dudas como la figura de mayor relieve durante las dos décadas anteriores a la guerra. Sus trabajos demuestran un profundo nivel de erudición y una complejidad teórica que le granjearon un considerable prestigio a nivel internacional. Y, sin embargo, no dejaron de verse animados por un deformador esencialismo historiográfico, que alcanzó quizá su máxima expresión en el amargo contexto de la Guerra Civil.

\section{La configuración de la disciplina orientalista en España. El giro hacia la historia interna de al-Ándalus}

A lo largo del siglo xix, la implantación en España de un marco de estudios orientales modernos provocó todo un proceso de revaloración del pasado musulmán y judío de la península ibérica. Por encima de otras consideraciones, este desarrollo fundamentó una reflexión de fondo por la que se problematizaba bajo nuevas perspectivas la relación que ese pasado 
semítico guardaba con la historia percibida propiamente como española. Figuras como José Antonio Conde (1766-1820), Pascual de Gayangos (1809-1897), José Amador de los Ríos (1816-1878) o Francisco Fernández y González (1833-1917), entre otros, fueron consolidando a través de sus obras un verdadero debate de amplio alcance en torno al grado de pertenencia de las letras árabes y hebreas en el patrimonio cultural de la nación española (López García 2011; Rivière Gómez 2000). Si bien es cierto que esta problematización de la historia medieval abrió nuevas vías por las que poder plantear la influencia del legado dejado por musulmanes y judíos sobre la propia conformación cultural de lo hispano, el orientalismo tendió en general hacia un historicismo por el que iba a quedar configurado como una herramienta auxiliar del gran proyecto historiográfico decimonónico: el relato nacional. Lo importante era lo que este orientalismo podía decir sobre aspectos hasta entonces más o menos desconocidos de la historia verdaderamente nacional, y esta no dejaba de ser la historia que se había construido sobre el hacer de las poblaciones cristianas medievales que habían protagonizado la Reconquista, un concepto historiográfico que precisamente estaba cristalizando en esta época (Ríos Saloma 2011).

El orientalismo historicista encontró su máxima expresión en la obra de Francisco Codera (1836-1917). Movido por una rigurosidad positivista digna de encomio, aunque rayana en lo obsesivo, Codera consagró su carrera a contrastar el corpus documental del medievalismo español con las fuentes árabes de carácter historiográfico de las que pudo hacer uso, buscando tanto certificar la veracidad factual del relato nacionalista como iluminar algunos aspectos hasta entonces poco estudiados de la historia nacional, tales como el origen altomedieval del reino aragonés (Viguera 2004). La clave, por tanto, residía en poner la historia andalusí al servicio de la narrativa nacional, bajo saludables propósitos de precisión historiográfica, eso sí. Por ello, Codera no cesó de insistir en la necesidad de formular una agenda de investigación para el orientalismo español basada en el escrutinio de la historia externa de al-Ándalus (Codera 189o), haciéndose eco de la terminología historiográfica del momento, lo que suponía renunciar al estudio de diversos aspectos culturales para centrarse exclusivamente en las fuentes relativas a la historia política de la 
presencia islámica en la península. Este planteamiento tendría una gran influencia sobre la práctica del orientalismo español durante las primeras décadas de la Restauración. En esos años, el énfasis en la historia externa que demandaba Codera iba a causar que quedase atenuada de forma considerable la sensibilidad que el orientalismo español de mediados de siglo había mostrado hacia la búsqueda de influencias semíticas en el devenir de la cultura española, ya fuera en forma de prestamos lingüísticos, de emulación de modelos literarios, o de adopción de figuras administrativas e instituciones políticas. En cualquier caso, la posibilidad de que se hubieran producido contactos o influencias de este tipo al nivel del discurso teológico entre cristianos, judíos y musulmanes, o el que hubiera podido surgir alguna forma de hibridación en las formas de religiosidad ibéricas, había quedado generalmente al margen de los debates decimonónicos. Serían los discípulos de Codera, Julián Ribera (1858-1934) y Miguel Asín Palacios, quienes abrirían de nuevo dentro del orientalismo español la investigación en el campo de la historia interna a través del estudio de las formas culturales específicas de la experiencia histórica andalusí. Y lo harían precisamente dando un papel privilegiado al análisis de la religiosidad y la teología islámica.

Quizá el hecho más peculiar dentro de este giro culturalista en el orientalismo español, que se inició precisamente en los años del cambio de siglo, es que iba a ser abordado desde posiciones netamente conservadoras (Bornstein 2019; García Sanjuán 2016). Y, sin embargo, tendría como resultado la mayor vindicación hecha en España del valor del pensamiento y obra de diversos autores musulmanes, llegando incluso a afirmar la determinante influencia que estos habían tenido sobre el desarrollo del escolasticismo cristiano. Tanto Ribera como Asín Palacios eran intelectuales profundamente católicos (Asín, de hecho, se había ordenado sacerdote en 1895). Su incursión en el complejo estudio de las transferencias culturales entre el islam y el cristianismo medieval quedaría mediatizada por la vinculación de ambos autores con un movimiento transnacional que se estaba desplegando por Europa en favor de una denominada «ciencia católica». Se trataba de un movimiento de apologética católica que, desde una postura radicalmente crítica hacia algunas de las consecuencias filosóficas de la ciencia positivista y evolucionista, defendía, sin 
embargo, la necesidad de que los católicos participasen en actividades de investigación científica, buscando así dar respuesta a algunas de las aporías que el imparable proceso de secularización generaba dentro de aquellos sectores del mundo católico más interesados en la ciencia moderna (Motzskin 1989). Desde un planteamiento muy general - a la vez que poco definido-sobre el tipo de actividades y disciplinas que constituían el concepto de ciencia que estos autores manejaban, y que sin duda alguna incluía de forma central a las humanidades - a las que, de hecho, daban una posición privilegiada-, los adalides de la ciencia católica buscaban redefinir la conflictiva relación entre religión y ciencia moderna en base a los términos de armonía entre razón y fe que había manejado tradicionalmente la escolástica tomista (Rodríguez de Cepeda 1897). De esta forma, los esfuerzos del movimiento por la ciencia católica se enmarcaban dentro del proyecto neotomista propugnado por el pontificado de León XIII (1810-1903).

La aparente paradoja que se desprende del hecho de que fueran precisamente autores católicos conservadores quienes llegaran más lejos a la hora de reivindicar la importancia del legado musulmán para la España cristiana, exige una interpretación historiográfica sobre el curso que tomó la investigación arabista en España a principios del siglo xx a partir de la profundización en el estudio de la historia interna andalusí. La explicación ex post facto dada por Asín en 1940 sobre la presencia de tropas marroquíes en el bando franquista se hace incomprensible sin atender a la trayectoria de los discípulos de Codera. Independientemente del grado de manipulación que la propaganda franquista hiciera del corpus bibliográfico del orientalismo español, o del nivel de oportunismo que el propio Asín pudiera haber mostrado en el marco de la inmediata posguerra, su artículo «Por qué lucharon a nuestro lado los musulmanes marroquíes» refleja con gran precisión una serie de ideas y nociones historiográficas sobre las que venía trabajando desde hacía décadas. Un hito destacado en la nueva orientación que iba a tomar el arabismo español tuvo lugar con la participación de Ribera y Asín en un volumen homenaje a Marcelino Menéndez Pelayo (1856-1912), organizado en 1899 por diversos intelectuales conservadores, lo que a su vez pone de relieve la proximidad ideológica que estos arabistas iban a guardar con el autor de la Historia de los 
heterodoxos españoles. Los trabajos de Ribera y Asín en ese volumen se centraron en analizar la presencia de elementos orientales en la obra del místico medieval Ramon Llull (1232-1315), pero a la vez guardaban una relación directa con los trabajos que Ribera venía elaborando desde hacía algunos años acerca de las instituciones educativas en el mundo islámico (Ribera 1893). Según aclararía el mismo Ribera unos años más tarde, estas investigaciones le habían llevado a convencerse de que a lo largo de los siglos x y xI habían penetrado en el mundo islámico claras influencias de diversas escuelas monásticas cristianas orientales, dentro de las cuales había perdurado a través de los siglos un fondo de filosofía griega clásica. Ribera aseguraba entonces que «la vida monástica de los musulmanes y las reglas de sus órdenes religiosas se derivan de las cristianas de los ritos orientales, [y por tanto] se puede enlazar eslabón tras eslabón la cadena que une todas las tradiciones» (Ribera 1904, 16).

Tanto para Ribera como para Asín, la obra de Llull podía y debía ser estudiada como una manifestación más de esa sucesión de intercambios religiosos que hacían de España un punto clave para la comunicación entre Oriente y Occidente. La singularidad del pensamiento del místico mallorquín y su difícil catalogación dentro de las corrientes de la escolástica del siglo XIII animaban a Ribera a buscar elementos externos al marco cristiano que permitiesen aportar nueva luz sobre la génesis de su obra. Y los encontraría en la figura del místico sufí murciano Ibn Arabi (1165-1240). Los paralelismos que Ribera veía entre ambos autores le llevó a sugerir la existencia en la obra de Llull de un claro deseo de emulación de los conceptos utilizados por el místico andalusí, hasta el punto de describir a Llull como un «sufí cristiano», y a su imitación del modelo sufí nada menos que como «el punto de arranque de la mística cristiana» (Ribera 1899, 215). Asín, por otra parte, exploraba en su texto la veta abierta por Ribera, con la intención de ahondar en el complejo campo de esas transferencias teológicas. El hallazgo de Ribera, poniendo en relación a Llull con Ibn Arabi, permitía realizar un nueva interpretación del pensamiento del sufí murciano, percibido ahora por Asín como un sistema sincrético en el que se fundían distintos elementos orientales bajo el denominador común del neoplatonismo alejandrino. Recogiendo la hipótesis central de Ribera, según la cual el cristianismo oriental, a través 
de escuelas como la nestoriana, había conservado ese fondo de filosofía clásica, que luego habría pasado a los pensadores peripatéticos musulmanes en la edad media, Asín fundamentaba el gran mérito de Llull en «hacer entrar en la corriente de las ideas cristianas medioevales, purificado de su levadura musulmana, un producto que quizá no era otra cosa más que transformación muslímica de antigua filosofía cristiana» (Asín 1899, 254-255). Esta cadena de intercambios religiosos tenía a España como el eslabón clave que permitía unir a Oriente y Occidente, gracias a figuras como Llull e Ibn Arabi.

Se ha señalado ya la vinculación de estos arabistas con los planteamientos de León XIII. Asín concluía su colaboración en el volumen homenaje a Menéndez Pelayo precisamente aludiendo a la encíclica Aeternis Patris, de 1879, que animaba a la recuperación de la escolástica tomista. Justificaba de esta forma una línea de investigación que potencialmente podía suscitar incomprensión en un público católico poco acostumbrado a mirar con buenos ojos el legado musulmán. A pesar de ello, Asín argumentaba que, al igual que algunos autores medievales como Llull no habían dudado en adoptar de la filosofía árabe «lo que en ella encontraban de utilizable para adaptarlo a la dogmática cristiana», igualmente «debemos en nuestros días aprovechar todo aquello que de legítimo progreso aparezca en la literatura filosófica contemporánea, seguros de que así haremos avanzar a la filosofía cristiana más y mejor, que permaneciendo petrificados en los textos que ya pasaron» (Asín 1899, 255-256). En esa empresa, Asín recibiría el valioso respaldo de Menéndez Pelayo, quien en 1902 prologaba con «verdadera satisfacción patriótica» la publicación de una obra del joven arabista aragonés sobre el filósofo y teólogo persa Al-Ghazali (1057-1111), expresando la importancia que tenía esta obra para poder sondear la filosofía oriental, «sin la cual serían ininteligibles los orígenes y desarrollo de la nuestra» (Menéndez Pelayo 1901, 9). Según Menéndez Pelayo, la defensa del sentimiento religioso de Al-Ghazali dentro de sus planteamientos filosóficos reflejaba la profunda moralidad de un «hombre en suma que merecería haber sido cristiano». Al igual que había hecho Asín en su alusión a la encíclica papal, Menéndez Pelayo también se veía en la necesidad de justificar la publicación de una obra que podía causar estupor entre un público católico, manifestando que «para nadie debe ser moti- 
vo de escándalo la singular historia de un místico musulmán que viene a través de los siglos suministrando armas a los más sabios defensores del dogma cristiano» (Menéndez Pelayo 1901, 36-37).

A lo largo de las primeras décadas del siglo xx, Asín seguiría profundizando en la concepción del cristianismo oriental como mediador entre el neoplatonismo clásico y el pensamiento islámico medieval, tesis que compartía con Ribera. En 1914 Asín publicaba una obra sobre Ibn Masarra (883-931) — basada en su discurso de recepción de ese mismo año en la Real Academia de Ciencias Morales y Políticas-, un místico cordobés a quien daba el crédito de haber introducido el sufismo oriental en al-Ándalus. El arabista aragonés retomaba en ese texto el problema de la génesis del misticismo islámico, razonando que el islam proponía una teología tan insuficiente, tanto desde un punto de vista filosófico como de vivencia religiosa, que había forzado a los pueblos no árabes que habían ido quedando bajo su dominio a reelaborar los dogmas islámicos siguiendo modelos externos al islam. El resultado había sido una proliferación de movimientos ascéticos, extraños a los fundamentos originales del islam, que debían mucho al contacto con el mundo cristiano oriental: «Para mí, el sufismo en sus orígenes es un simple caso de imitación, que tiene mucho de consciente, del monacato cristiano oriental» (Asín 1914, 13). Partiendo de esa conexión, Asín esbozaría la existencia dentro de la escolástica medieval occidental de una tendencia marcada por una fundamentación más neoplatónica que aristotélica, y que, por tanto, era deudora en buena medida del pensamiento de Ibn Masarra y de Ibn Arabi, fiel seguidor del místico cordobés. Fue un argumento que le daría fama internacional a Asín - no exenta de gran polémica - cuando en 1919 incluyese a Dante Alighieri (1265-1321) dentro de esa corriente, señalando la supuesta influencia de Ibn Arabi y de la escatología islámica en la Divina comedia (Asín 1919).

Dando un salto en su producción académica, en 1931 el arabista aragonés iba a ofrecer en su obra El islam cristianizado la versión más elaborada de su interpretación teórica sobre los puntos de convergencia teológica entre el islam y el cristianismo. El prólogo de esta obra incidía de nuevo en la filiación cristiana del ascetismo islámico, apuntando Asín que la narración coránica de la vida de Mahoma no permitía concebir un ideal de 
vida mística, por lo que los sufíes se habían visto forzados a reelaborar con posterioridad la imagen del profeta, cristianizándola. Tomando a Ibn Arabi como modelo ideal de la mística islámica, la obra buscaba señalar «las posibles analogías que esta ofrezca con la cristiana», confirmando así la existencia de una espiritualidad islámica «con caracteres estrechamente análogos a los de la cristiana» (Asín 1990, 7). Aún más, según Asín, el propio Tomás de Aquino (1225-1274), el gran representante de la escolástica cristiana, se habría inspirado a la hora de teorizar diversos dogmas cristianos - tales como el de la visión beatífica - en la obra de autores andalusíes como Averroes (1126-1198) y Avempace (1085-1138), quienes a su vez habían recibido cierto influjo del misticismo sufí. El monacato cristiano oriental se presentaba claramente ante los ojos de Asín como la indiscutible matriz que habría dado forma tanto a la ascética islámica como a la cristiana occidental. A través de la emulación consciente de autores musulmanes, los teólogos cristianos medievales como Aquino o Llull demostraban «la fundamental analogía que para ellos existía entre las dos espiritualidades, cristiana e islámica» (Asín 1990, 11).

Vemos entonces que ya en 1931, varios años antes de sentir la necesidad de justificar la presencia insólita de tropas marroquíes en el bando franquista durante la guerra, Asín se estaba planteando la posibilidad de salvación de los musulmanes como un problema teórico central, en una obra a caballo entre tratado teológico y monografía sobre la historia del misticismo islámico. Convencido de la capacidad de perfección espiritual de algunos místicos sufíes, Asín evocaba la actitud de aquellos teólogos cristianos - entre los que contaba al Doctor Angélico- que habían planteado que la salvación era posible fuera del cristianismo, siempre que mediara la creencia en un Dios creador, providencialista y remunerador. A esto Asín añadía la cercanía que los místicos musulmanes sentían hacia la figura de Jesucristo, considerado como profeta por el islam a pesar de la negación del dogma de la Trinidad, y cuya vida era idealizada como modelo de perfección moral entre los sufíes. De esta forma, el sacerdote arabista planteaba desde un punto de vista teológico la existencia de medios de salvación alternativos a los métodos ordinarios establecidos por la Iglesia «para aquellos individuos a quienes por razones geográficas o históricas la economía del plan general de la Providencia no hay manera 
que les aproveche». Un caso paradigmático de esa economía de salvación se podía descubrir entonces en «la historia del sufismo musulmán». Según Asín, la adopción abierta del cristianismo había sido un imposible dentro de un marco social regido por la ortodoxia islámica, de forma que la divina providencia actuaba por otras vías para facilitar la conversión de los sufíes «del islamismo puro y simple, a un cristianismo parcial, velado por apariencias musulmanas en lo dogmático, pero eficaz en lo moral y en lo ascético» (Asín 1990, 24-25).

\section{De la guerra colonial a la Guerra Civil}

La presencia de tropas marroquíes en la Guerra Civil es un fenómeno indisociable de la historia colonial española en Marruecos. Dentro de la situación estructural de guerra colonial en la que se produjo la intervención española en el país norteafricano, la incorporación de nativos marroquíes en el Ejército español precedió incluso a la creación en 1912 del protectorado español. Ese mismo año, significativamente, el líder tribal que dirigía la resistencia rifeña a las tropas españolas, Mohamed Ameziane (1859-1912), caía muerto a manos de uno de los nuevos reclutas indígenas que habían ido quedando integrados en el Ejército desde el año anterior (Madariaga 2009, 92). La lucha colonial iba a proporcionar el contexto fundamental para la gradual militarización de un discurso africanista que, a inicios de siglo, había espoleado la penetración colonial en África presentándola como una forma de contribuir a la regeneración nacional a través del comercio y la acción civilizatoria. A medida que el protectorado se fue convirtiendo en feudo de la oficialidad africanista, esta llegaría a conformar una mentalidad propia, articulada sobre la idea de que en Marruecos se encontraba la posibilidad de redención nacional para una patria española en decadencia (Iglesias 2016, 99-104). La debacle de Annual en 1921, que dejó millares de muertos españoles en los campos marroquíes, acentuó el creciente distanciamiento entre el Ejército colonial y la clase política española. Bajo el telón de fondo de la guerra colonial se forjó el núcleo duro de una oficialidad africanista que tendría posteriormente gran representación entre los líderes del que llamaban Alzamiento Nacional de julio de 1936. Fue en Marruecos donde 
Franco estableció vínculos con varios de estos oficiales, y la experiencia de la guerra colonial iba a tener un gran peso en el desarrollo de la Guerra Civil (Casals 2006; Macías Fernández 2019).

A pesar del relato sublimado de algunos de los oficiales africanistas sobre su experiencia vital en África, como el del propio Franco, la visión que estos tenían de los nativos distaba de ser positiva. Esta visión se estructuraba frecuentemente en base a una serie de prejuicios históricos de marcada islamofobia. Las necesidades de guerra a partir del verano de 1936 iban, por tanto, a exigir una resignificación forzada de las representaciones habituales de los moros, ahora convertidos en una de las mejores armas del Ejército nacional (Velasco de Castro 2014). En ese nuevo contexto bélico, las ideas historiográficas del arabismo representado por Asín se demostrarían muy útiles para la propaganda franquista. La prevalencia hasta entonces de estereotipos negativos seculares en el discurso africanista quedaba claramente plasmada en el frecuente uso del término «reconquista" para aludir al esfuerzo militar por recuperar el control sobre el protectorado marroquí tras Annual, uso que enraizaba bien con el deseo de venganza que se extendía por buena parte de la sociedad española en 1921 (Nerín 2005, 14). Tras la pacificación del territorio entre 1925 y 1927, un reforzado sistema de intervenciones militares, apuntalado por el general José Sanjurjo (1872-1936) desde su cargo como alto comisario, buscaba hacer de los caídes y líderes tribales locales los ejes del control colonial sobre el Rif, recurriendo al soborno como medio principal de persuasión. Los caídes quedaban, así, convertidos en funcionarios de la Administración colonial, recibiendo pagas regulares. Este sistema organizado en torno a los notables tribales sería clave a la hora de movilizar reclutas marroquíes durante la Guerra Civil (Madariaga 2006, 153-160).

La intervención de soldados marroquíes en acciones militares en la metrópoli no fue un hecho exclusivo de la Guerra Civil. Gobiernos de distinta orientación habían hecho uso de ellos con anterioridad para sofocar levantamientos contra el orden republicano, en 1932 con motivo de la Sanjurjada, y en 1934 ante la revolución obrera en Asturias (Mesa 2004, 25-26). A lo largo de su trayectoria en el Ejército colonial, las tropas nativas fueron empleadas fundamentalmente como tropas de choque, una función que también cumplirían en la Guerra Civil. Su participación en la contienda 
tuvo lugar desde un primer momento, siendo clave su presencia en las acciones de primera hora para asegurar el control del protectorado marroquí por parte del bando sublevado (Mesa 2004, 28-32). En las vísperas del golpe del julio de 1936, se calcula que el Ejército de África contaba con cerca de cuarenta mil efectivos, diecisiete mil de los cuales eran nativos marroquíes. Estos últimos asumirían un papel especialmente destacado en las acciones bélicas iniciales en el protectorado marroquí debido a la desconfianza que guardaban los mandos africanistas hacia las tropas de leva, sospechosas de simpatizar con la República. Las estimaciones sobre el número total de marroquíes que participarían en el conflicto entre 1936 y 1939 oscilan entre sesenta y setenta y cinco mil (Madariaga 2006, 165, 171-172). El franquismo haría insistentemente alusión a la voluntariedad entusiasta de los soldados marroquíes, fruto de una comunión de valores compartidos con la causa nacional, algo que choca frontalmente con la interpretación del historiador marroquí Abdelhajid Benjellon, quien ve el reclutamiento de marroquíes en el marco de la Guerra Civil como una forma extrema de explotación colonial, y la supuesta voluntariedad de los mismos «determinada por su condición objetiva de colonizados, utilizados como simples medios» (Benjellon 1988, 528). María Rosa de Madariaga ha puesto de manifiesto la importancia del contexto de penuria económica en el Rif como telón de fondo de los reclutamientos, iniciados tras dos años de malas cosechas dentro de una sociedad eminentemente agraria (Madariaga 2006, 166). A medida que la guerra avanzaba, se fue haciendo cada vez más difícil para los mandos franquistas mantener el ritmo de alistamientos, a la vez que se producían actos de protesta en el protectorado, e incluso circulaban rumores de un posible levantamiento general en el Rif contra la Administración colonial. Ante esta situación, los métodos de reclutamiento se volverían cada vez más coercitivos, incluyendo el fusilamiento de cadíes que se habían mostrado contrarios a los mismos (Madariaga 2006, 174-176, 184-186).

\section{Por qué lucharon los marroquíes del lado de Asín Palacios}

Como ya se ha señalado, la propaganda franquista dedicó enormes esfuerzos a explicar la presencia de las tropas marroquíes en función de una suDICTATORSHIPS \& DEMOCRACIES 8 (2020) - E-ISSN: 2564-8829 - PUNCTUM, UNIVERSITAT OBERTA DE CATALUNYA \& FUNDACIÓ CARLES PII SUNYER 
puesta comunidad de ideales. La gran importancia militar que tuvieron los marroquíes en el desarrollo de la guerra se manifiesta en la constante negativa de Franco a retirarlos del escenario bélico, a pesar de que, ante las presiones del Comité de No Intervención, sí llegase a aceptar la salida de voluntarios italianos y portugueses (Nerín 2005, 171). Las autoridades franquistas trataron por todos los medios de mantener la moral entre las unidades africanas destacadas en la península, procurando satisfacer en todo momento las necesidades religiosas de los soldados (Wright 2020). Entre la batería de argumentos a la que la propaganda franquista recurría para explicar la entusiasta movilización de los musulmanes marroquíes, primaba la idea de que estos habían respondido a la necesidad de defender los valores tradicionales de familia, patria y religión, amenazados por el marxismo antirreligioso de los republicanos. Es cierto que en los meses anteriores al conflicto el movimiento nacionalista marroquí había visto con desconfianza ciertas políticas del Gobierno del Frente Popular en materia religiosa, y que una vez iniciadas las hostilidades, los cadíes al servicio de la red de interventores militares proclamaron en las cabilas la necesidad de alistarse en el Ejército franquista, apoyándose en un discurso religioso que incitaba a la yihad contra los ateos infieles (Mesa 2004, 120-124). Sin embargo, y pese a reconocer la posibilidad de que se llegase a desarrollar un verdadero sentimiento de apego a Franco y una manifiesta hostilidad hacia los rojos entre las cabilas rifeñas, María Rosa de Madariaga insiste en que, más allá de la propaganda religiosa, la realidad efectiva que propició los reclutamientos masivos estuvo fundamentalmente motivada por la necesidad económica de los marroquíes. Señala, de esta forma, que la participación de combatientes marroquíes en la Guerra Civil respondía a una tendencia que fue general en toda la historia del protectorado marroquí, por la cual la colaboración con el Ejército colonial repuntaba en años de malas cosechas (Madariaga 2006, 167-170). Esta afirmación es consistente con el hecho de que las misivas que los reclutas marroquíes enviaban a sus familiares desde el frente apenas hacían alusión a temas políticos o religiosos, mientras que sí manifestaban una constante preocupación por comprobar que los destinatarios habían recibido envíos de dinero (Nerín 2005, 219). 
El propio Franco definió en noviembre de 1937 el conflicto como una guerra religiosa compartida: «Nosotros, todos los que combatimos, cristianos y musulmanes, somos soldados de Dios y no luchamos contra hombres, sino contra el ateísmo y el materialismo» (citado en Casals 2006, 214). Esta interpretación sería asumida por Asín Palacios en «Por quélucharon a nuestro lado los musulmanes marroquíes». La mirada ofrecida por el arabista aragonés en ese artículo de posguerra trascendía, sin embargo, el mero análisis de un episodio coyuntural en la lucha contra el materialismo. Asín, por el contrario, creía ver en la participación de los moros en la Guerra Civil la confirmación de su heurística historiográfica, la armonización entre el evento histórico y su particular esquema providencialista de economía de salvación. Haciendo honor al pronombre interrogativo del título del artículo, Asín iniciaba su indagación cuestionando las posibles razones que podían haber motivado la «fervorosa adhesión» de los marroquíes «a nuestro Ejército y a nuestra Causa» (Asín 1948, 127). El arabista descartaba de plano los móviles materiales, aduciendo que la modesta paga que recibían los marroquíes no podía considerarse como razón suficiente, sin dar en ningún momento detalle alguno sobre lo que percibían los reclutas, ni hacer referencia de ningún tipo al contexto económico del Rif. Descartaba igualmente motivaciones políticas, sin aludir a las declaraciones ambiguas de la propaganda franquista durante la guerra sobre la posibilidad de conceder algún tipo de autonomía al protectorado marroquí tras el conflicto, dirigidas a ganarse el apoyo, o al menos el silencio, de los nacionalistas marroquíes de cara a su continuo reclutamiento. Curiosamente, en este respecto parecía incluso contradecir el discurso oficial en el protectorado, el cual ensalzaba constantemente los beneficios que la población nativa obtenía de la tutela colonial, ya que en su argumentación Asín aseguraba que la voluntad nacional de un pueblo sometido a un régimen colonial debía naturalmente tender a su autonomía o a su independencia. Bajo ese punto de vista, Asín mantenía que a pesar de que la benevolencia de las autoridades coloniales españolas hacia los marroquíes había conseguido neutralizar los intentos de insurrección anticolonial fomentados por el marxismo internacional, la participación de marroquíes en el conflicto peninsular no favorecía los intereses nacionales de los marroquíes. Concluía, de esta manera, el ara- 
bista aragonés que la popularidad de los reclutamientos no se podía explicar en función de razones conscientes, haciéndose necesario, por tanto, una interpretación fundamentada en estímulos inconscientes, aquellos que «arrastran al hombre en dirección contraria a la que dicta su interés» (Asín 1948, 127-129). La acción bélica de los marroquíes quedaba, así, definida en términos de sacrificio.

El artículo de Asín parecía también poner en cuestión uno de los argumentos clásicos del africanismo español, que desde finales del siglo xIX había justificado el derecho español de colonizar Marruecos en base a la existencia de una supuesta identidad racial compartida entre españoles y marroquíes, forjada a lo largo de siglos de historia en común que se remontaban por lo menos a los siglos de la conquista islámica. Asín admitía la importancia de la mezcla de elementos étnicos tras siglos de convivencia medieval. Sin embargo, alegaba que incluso en el caso de dar por buenas las ideas racialistas, por las que a cada grupo étnico cabía atribuirle una mentalidad específica, la noción de «raza pura» no podía ser más que un mito en un caso como el español, en el que tantos pueblos habían contribuido a conformar el carácter físico de sus habitantes. No quedaba, por tanto, más que entender el sacrificio de los marroquíes como resultado de una afinidad de tipo espiritual con los valores de la España tradicional, amenazados por la utopía soviética que enarbolaba el Ejército republicano (Asín 1948, 128-130). Asín, por supuesto, era consciente de lo paradójico que podía resultar tal interpretación en un país donde la identidad colectiva se había forjado durante siglos en torno a una narrativa que exacerbaba el enfrentamiento entre moros y cristianos. Y, sin embargo, sus propias investigaciones orientalistas ponían de manifiesto lo inexacto y prejuicioso de esa visión de alteridad radical. Ante «la investigación serena y objetiva de los hechos culturales latentes bajo la historia externa de las gestas guerreras», no cabía más que afirmar que «el Islam en general, y más concretamente el español, del que es hermano legítimo el marroquí, ofrece afinidades muy estrechas con la cultura occidental y, sobre todo, con la civilización cristiana española» (Asín 1948, 131).

En función de esa insospechada afirmación sobre la afinidad entre el islam y el catolicismo español, especialmente imprevisible en tanto que proveniente de un sacerdote, Asín buscaba demostrar la coherencia lógi- 
ca del compromiso adoptado por los marroquíes en el conflicto español y la armonización entre la realidad de los reclutamientos y el discurso franquista, de corte maurrasiano, que aunaba nacionalismo y religiosidad bajo los valores de familia, patria y religión, un discurso que había sido sustentado durante la guerra por buena parte del alto clero español (Nerín 2005, 96-97). La lucha entre España y la anti-España, exacerbada como conflicto religioso, era planteada no ya en términos de Guerra Civil, sino, como el propio arabista aragonés afirmaba, de «Reconquista». Solo que en esta ocasión no se trataba de una lucha de cristianos contra musulmanes, sino que los defensores de ambas confesiones, herederos de una espiritualidad común, protagonizaban un mismo combate sagrado contra las huestes del materialismo ateo en su afán por subvertir los principios de la civilización occidental, cuya defensa paradójicamente recaía, al menos parcialmente, en los mismos moros contra los que se había invocado al apóstol Santiago durante siglos. La Guerra Civil aparecía así no solo como cruzada, sino que, siguiendo la lógica de este discurso, podía interpretarse igualmente como yihad. Para sustentar la analogía entre ambas espiritualidades, Asín pasaba entonces a desarrollar punto por punto aquellos elementos en los que cristianismo e islam guardaban una mayor cercanía dogmática. Según él, los teólogos de ambas religiones compartían argumentos similares a la hora de demostrar la idea monoteísta. Asimismo, concedían a la divinidad atributos similares, a la vez que defendían la libertad y responsabilidad moral de los hombres. Las semejanzas se extendían también sobre conceptos como la revelación, la resurrección de los muertos, el juicio final, o la cuestión de las penas y castigos de ultratumba (Asín 1948, 132-133).

Pero si todos estos puntos de encuentro entre ambas religiones permitían reconocer la verosimilitud de una hermandad espiritual construida sobre unos dogmas muy próximos entre sí, había un escollo muy difícil de salvar en la negativa islámica a reconocer la divinidad de Cristo, y por tanto del dogma de la Trinidad. Es en este punto donde la originalidad de las investigaciones de Asín y del orientalismo español servían para disipar la confusión. Junto con el Corán, el islam considera las tradiciones sobre la vida de Mahoma o hadices como fuentes de la revelación divina, y Asín señalaba que existía toda una corriente muy extensa de narraciones 
de este tipo dirigidas a acentuar la alta espiritualidad y perfección moral de Jesucristo. Eran narraciones de filiación monástica y cristiana, en su opinión, que evidenciaban por encima de cualquier otro hecho la cadena de contactos culturales medievales que tanto él como Ribera (fallecido en 1934) se habían esforzado en poner de manifiesto durante años, desde que en 1899 habían defendido la proximidad entre las ideas de Llull y de Ibn Arabi en su contribución al volumen homenaje a Menéndez Pelayo. La veneración islámica de la figura de Jesucristo, consecuencia de estas hibridaciones teológicas, explicaba un hecho tan insólito como el ver la imagen del Sagrado Corazón de Jesús en el pecho de algunos reclutas marroquíes durante la guerra, algo que, según Asín, había generado gran perplejidad entre los españoles y que, sin embargo, no era sino «supervivencia inconsciente de esa veneración religiosa que los musulmanes todos profesan a Jesucristo y a su madre la Virgen María» (Asín 1948, 136). Asín añadía que la emulación de modelos monásticos y ascéticos cristianos había sido especialmente pronunciada entre los místicos sufíes, y mantenía que muchas prácticas de vida ascética de origen cristiano aún perduraban entre las cofradías religiosas del norte de Marruecos, particularmente populares en las regiones de donde eran naturales la mayor parte de los soldados marroquíes. Lo cierto es que los mandos franquistas tuvieron que recurrir a algunas de estas hermandades religiosas para facilitar los reclutamientos en el Rif en los momentos en los que se dio una mayor oposición local a los mismos, y que incluso una delegación de estas cofradías viajó en cortejo a Tetuán — capital del protectorado- en diciembre de 1937 para mostrar su adhesión a la causa franquista (Madariaga 2006, 181, 244).

Destaca en el artículo de Asín la voluntad de desterrar prejuicios sobre el islam que estaban hondamente arraigados en la mente de los españoles. De la misma forma que combatía la extendida opinión sobre el fatalismo musulmán, incidiendo sobre la importancia que se daba a la responsabilidad moral del creyente, Asín rechazaba también el habitual estereotipo sobre la sensualidad desbocada de los musulmanes. Asín contraponía esta prejuicio con una alusión a la supuesta frecuencia con la que los reclutas marroquíes en España desviaban sus miradas de fotografías con desnudos femeninos, a la vez que atribuía a calumnias de la prensa marxistas 
las acusaciones de violaciones realizadas por estos durante su estancia en la península (Asín 1948, 145). Lo impostado de la argumentación de Asín, en su voluntad de enraizar la acción militar de los marroquíes con su teorización sobre la compartida espiritualidad entre musulmanes y cristianos, llegaba a un paroxismo cómico con su alusión al testimonio de un periodista que había sido presuntamente testigo del asalto de un combatiente marroquí en una trinchera enemiga en Madrid al grito de: «Tú no estar de Mahoma! ¡Tú no estar de derechas!» (Asín 1948, 145). Sea como fuere, la insólita participación de los marroquíes en el teatro de guerra español, a los ojos del sacerdote arabista, reflejaba por encima de todo la existencia de una afinidad subterránea entre el islam y la cultura occidental, forjada gracias a la convivencia religiosa que durante ocho siglos había tenido lugar en la España medieval:

Bajo la áspera corteza de esos rudos y valientes soldados marroquíes palpita un corazón gemelo del español, que rinde culto a unos ideales ultraterrenos, no muy dispares de los nuestros, y que siente las vivas emociones religiosas que nosotros sentimos, porque profesa muchos de los dogmas cristianos que nosotros profesamos y que el marxismo ateo repudia y persigue con ensañamiento. (Asín 1948, 148-149)

\section{Epílogo}

La obra historiográfica de Asín - y especialmente su artículo de 1940 - se erigió durante el primer franquismo como uno de los referentes centrales a la hora de consolidar la narrativa sobre la participación de combatientes marroquíes en la Guerra Civil, así como para apuntalar la nueva aproximación diplomática de España hacia el mundo árabe e islámico (Velasco de Castro 2014). Una clara señal de la consideración que mostró el régimen franquista hacia el arabista aragonés fue su nombramiento como vicepresidente del nuevo Consejo Superior de Investigaciones Científicas, creado tras la guerra en sustitución de la antigua Junta para la Ampliación de Estudios (Marín et al. 2009, 283). El peso del marco interpretativo de Asín durante el primer franquismo se percibe de forma especialmente clara en la obra de Tomás García Figueras (1892-1981), un 
militar africanista que iba a tener una participación destacada en la configuración del nuevo discurso franquista sobre el islam. Cercano a Franco, García Figueras se había labrado una carrera como interventor militar en el área vinculada a la ciudad marroquí de Larache antes de la guerra, y posteriormente ocuparía un destacado papel en el equipo que preparó el encuentro del caudillo con Hitler en Hendaya en 1940, que culminó con el conocido fiasco para las expectativas del dictador español de conseguir el apoyo de la Alemania nazi para hacerse con los territorios del Imperio francés en el norte de África (Jensen 2016, 184-185, 190). En 1939, García Figueras publicaba Marruecos (La acción de España en el norte de África), una obra que le haría merecedor al año siguiente del Premio Nacional Francisco Franco, y que iba a tener diversas reediciones a lo largo de los años. Concebida como una obra de divulgación sobre la relación histórica entre España y Marruecos, se convertiría pronto en el principal soporte ideológico de la acción colonial franquista en Marruecos, argumentando que la acción colonial española estaba alimentada exclusivamente por un ideal espiritual, algo que la diferenciaba del colonialismo materialista de otras potencias europeas. Según el propio autor, el motivo principal que le había impulsado a escribir ese libro había sido la constatación de la persistente perplejidad que causaba entre los españoles la participación de marroquíes en la Guerra Civil. Se propuso entonces poner de manifiesto la existencia de una realidad fraternal entre ambos pueblos, en gran medida desconocida, por diversas razones, tanto en la España nacional como en la España roja, y que permitía llegar a la conclusión de que «el Islam está mucho más cerca del Cristianismo que de los sin Dios» (García Figueras 1955, 7).

Antes aún de que Asín publicara en 1940 su explicación de corte histórico-teológico sobre los voluntarios marroquíes en la Guerra Civil, García Figueras razonaba que se hacía necesaria una nueva lectura historiográfica de la relación de España con el islam, en la línea ya propuesta por el arabista aragonés en sus obras de preguerra, para poder comprender las nuevas realidades que se estaban conformando gracias a la presencia española en Marruecos. Frente a la estereotipada idea de una enemistad secular entre ambas religiones, si se analizaba más profundamente la realidad histórica medieval de la convivencia entre cristianos y musulmanes, 
«como lo ha hecho Asín Palacios», se podía constatar «que entre ambas religiones no existen tan grandes diferencias que justifiquen el odio exacerbado de ambos pueblos» (García Figueras 1955, 32). La situación bajo la nueva España de Franco, encarnación de la «España auténtica», resurgida precisamente gracias a la generosa acción del Ejército en Marruecos, permitía restablecer la hermandad espiritual entre ambos pueblos como un primer paso hacia una nueva era en la que España y el mundo islámico forjarían una nueva alianza contra el imperante materialismo. El sacrificio de los marroquíes en la Guerra Civil sellaba, según García Figueras, esa fraternidad, que desde entonces caminaba unida «contra los hombres sin Dios que amenazaban hundir en el caos una cultura de Occidente de la que la hispanidad y el arabismo habían sido los mejores artífices» (García Figueras 1955, 10, 244). García Figueras se mantendría como un fiel colaborador de la política de Franco en Marruecos, desde donde continuaría insistiendo en la singularidad del colonialismo español, gracias a una extensa obra que abarcó también la narrativa de ficción, y que estaba dedicada a sostener la idea de la compatibilidad entre islam y cristianismo (Jensen 2016, 198). En 1953 elaboró incluso un extravagante compendio de composiciones poéticas sobre el Alzamiento Nacional en el que destacaba la alta proporción de piezas dedicadas a los soldados marroquíes, incluyendo poesías de autores como José María Pemán (1897-1981) o Agustín de Foxá (1906-1951).

Como se ha visto, el régimen franquista haría un uso extensivo de los esquemas interpretativos de autores como Asín Palacios o García Figueras. Esta instrumentalización, realizada con el fin de fomentar un discurso de cercanía con el mundo islámico, se volvería especialmente útil a medida que el creciente aislamiento internacional de España tras la derrota de los países del Eje en la Segunda Guerra Mundial forzaba al Estado franquista a orientar sus relaciones diplomáticas hacia los países árabes (Rein 1999). En este sentido, cabe destacar la tarea de la Casa de Marruecos en el Cairo, creada por las autoridades franquistas durante los años de la Guerra Civil con el objetivo de difundir la imagen de Franco como defensor del islam, apoyada precisamente sobre la noción de la espiritualidad compartida entre España y esta religión frente al rampante materialismo, y tomando la experiencia de los combatientes marroquíes en la Guerra Civil como 
un hito fundamental en esta empresa común (Madariaga 2006, 356). Paradójicamente, García Figueras afirmaba que la obra de España en el protectorado marroquí debía servir como el modelo hacia el que podían dirigir con ilusión sus miradas los millones de musulmanes que luchaban en el mundo para liberarse del colonialismo (García Figueras 1955, 369). Sin embargo, los estrechos límites de esta renovada fraternidad auspiciada por el franquismo - limitada exclusivamente al ámbito discursivose revelan de manera incuestionable en el trato extendido a los reclutas marroquíes tras el fin del conflicto. Mientras que Asín defendía que el sacrificio realizado por los marroquíes exigía reconocer el derecho a la ciudadanía española a quienes hubiesen combatido por la causa nacional, y a pesar de que muchos de ellos mostraron su voluntad de quedarse en la península, las autoridades franquistas procedieron a una política general de repatriaciones forzadas (Nerín 2005, 188). Si es cierto que se creó un organismo estatal para asistir a los veteranos marroquíes que habían sufrido mutilaciones como consecuencia de su servicio al Ejército franquista, el Benemérito Cuerpo de Mutilados de Guerra Marroquíes, dotado con un servicio de pensiones que se sostuvo en buena medida por las necesidades diplomáticas del régimen, las pensiones fueron siempre inferiores a las recibidas por los mutilados españoles, y quedaron suprimidas tras la independencia de Marruecos en 1956 (Wright 2020).

En gran medida, la propaganda franquista no hizo sino instrumentalizar las ideas de proximidad espiritual entre el islam y el cristianismo en función de sus más imperiosas necesidades prácticas durante la Guerra Civil, algo que había prefigurado ya el africanismo español a la hora de justificar la colonización de Marruecos. Esta función fue posteriormente exacerbada como resultado de las necesidades diplomáticas dentro del escenario internacional de la posguerra mundial. No obstante, la explicación de Asín sobre la participación de marroquíes en la contienda no puede entenderse meramente en función de ese reduccionismo oportunista. Existe un hilo argumental que recorre toda su obra y que encuentra en su artículo de 1940 la culminación de una teorización historiográfica sobre las transferencias culturales entre Oriente y Occidente, y que, en un giro teologizante, problematizaba estas cuestiones dentro de un esquema de economía de la salvación. Este artículo de posguerra es incomprensi- 
ble sin toda su producción académica anterior, y, realmente, apenas hay referencias en él a hechos concretos del conflicto o a aspectos sociológicos relativos a las poblaciones de donde provenían los combatientes marroquíes. Para el arabista aragonés era difícil sustraerse a la tentación de analizar el fenómeno de los reclutamientos desde el propio esquema interpretativo que él mismo había construido a lo largo de varias décadas. En este sentido, la conceptualización que hizo el primer franquismo de la hermandad espiritual de España con el mundo islámico es un resultado directo del propio desarrollo del orientalismo español, un desarrollo mediatizado por el encuentro entre la investigación del pasado medieval y las preocupaciones presentistas de sus actores principales.

Miguel Asín pensó genuinamente que un anhelo común y una historia compartida unía a españoles y a musulmanes, y, motivado por una serie de preocupaciones intelectuales que fueron también mutando a lo largo de varias décadas, reivindicó la importancia del impacto profundo que tuvo el legado musulmán andalusí en la vida española. Algo similar puede decirse de Tomás García Figueras, quien, inspirado por la obra del arabista aragonés, llegó a convencerse de que existía una conexión latente entre españoles y musulmanes por debajo de los prejuicios antagonistas seculares. Ambos manifestaron que el franquismo ofrecía la posibilidad de profundizar la hermandad espiritual que de alguna manera había perdurado de forma inconsciente a través de los siglos. La revisión historiográfica de la historia interna andalusí iniciada por Ribera y Asín encontraba, así, una oportunidad histórica en la nueva España de Franco para deshacer las imágenes tradicionales de alteridad, a través de la recuperación del supuesto ideal medieval por el cual habían vivido «bajo la tutela tolerante del Estado Católico las mezquitas y las sinagogas, acogidas al espíritu comprensivo de la España católica» (Asín 1948, 151). Es bastante dudoso que esa invocación a la tolerancia, encuadrada dentro del supremacismo teológico del nacionalcatolicismo, tuviese alguna capacidad de desarraigar unos prejuicios sobre la identidad nacional que estaban muy enquistados en España. No obstante, resulta innegable que la idea de la convivencia medieval ibérica recibió un impulso decisivo a la sombra del orientalismo español de la primera mitad del siglo xx. En este contexto, mediatizado en buena medida por el conservadurismo católico y por los 
problemas vinculados a sus intereses y a preocupaciones como las que dirigían el movimiento por la ciencia católica, se fue gestando una forma de entender el pasado medieval español, que luego se transformaría en agria polémica con las obras de Américo Castro (1885-1972) y Claudio Sánchez-Albornoz (1893-1984).

\section{Bibliografia}

Asín Palacios, Miguel. 1899. «Mohidín». Dentro de varios autores, Homenaje a Menéndez Pelayo en el año vigésimo de su profesorado, 217-256. Madrid: Librería General de Victoriano Suárez.

—.1901. Algazel. Dogmática, moral, ascética. Zaragoza: Comas Hermanos.

-1914. Abenmasarra y su escuela. Orígenes de la filosofía hispano-musulmana. Madrid: Imprenta Ibérica.

-1919. Discurso leído en el acto de su recepción por D. Miguel Asín Palacios y contestación de D. Julián Ribera Tarragó el día 26 de enero de 1919. Madrid: Imprenta de Estanislao Maestre.

—.1948. Obras escogidas, volumen 2 y 3. Madrid: Consejo Superior de Investigaciones Científicas.

-1990. El Islam cristianizado. Estudio del sufismo a través de las obras de Abenarabi de Murcia. Madrid: Hiperón.

Benjellon, Abdelhajid. 1988. «La participación de los mercenarios marroquíes en la Guerra Civil española». Revista Internacional de Sociología 4: 527-540.

Bornstein, Pablo. 2019. «An Orientalist Contribution to "Catholic Science": The Historiography of Andalusi Mysticism and Philosophy in Julián Ribera and Miguel Asín». Religions 10: 568.

Casals Meseguer, Xavier. 2006. «Franco “el Africano”». Journal of Spanish Cultural Studies 7 (3): 207-224.

Codera, Francisco. 189o. «Anteproyecto de trabajos y publicaciones árabes que la Academia debiera emprender». Boletín de la Real Academia de la Historia 16 (5): 395-404.

García Cruz, José Fernando. 2002. «Las fuerzas militares nativas procedentes del Protectorado de Marruecos: Transcendencia política de su aplicación en las operaciones militares durante la Guerra Civil española». Hispania Nova 2. http:// hispanianova.rediris.es/general/articulo/015/arto15.htm.

García Figueras, Tomás. 1953. «Mística y poesía del Alzamiento Nacional en Marruecos». Dentro Tomás García Figueras, Miscelánea de estudios varios sobre Marruecos, 235311. Tetuán: Editora Marroquí.

—. 1955. Cuarta edición. Marruecos (La acción de España en el norte de África). Tetuán: Editora Marroquí. 
García Sanjuán, Alejandro. 2016. «Al-Andalus en el nacionalcatolicismo español: la historiografía de época franquista (1939-1960)». Dentro Francisco J. Moreno Martín, ed., El franquismo y la apropiación del pasado: El uso de la historia, de la arqueología y de la historia del arte para la legitimación de la dictadura, 189-208. Madrid: Editorial Pablo Iglesias.

Iglesias Amorín, Alfonso. 2016. «La cultura africanista en el Ejército español (19091975)». Pasado y Memoria. Revista de Historia Contemporánea 15: 99-122.

Jensen, Geoffrey. 2016. «Muslim Soldiers in a Spanish Crusade: Tomás García Figueras, Mulai Ahmed er Raisuni and the Ideological Context of Spain's Moroccan Soldiers». Dentro Eric Storm y Ali Al Tuma, ed., Colonial Soldiers in Europe, 1914-1945: 'Aliens in Uniform' in Wartime Societies, 182-206. Nueva York: Routledge.

López Barranco, Juan José. 2006. El Rif en armas: la narrativa española sobre la guerra de Marruecos (1859-2005). Madrid: Mare Nostrum.

López García, Bernabé. 2011. Orientalismo e ideología colonial en el arabismo español (1840-1917). Granada: Universidad de Granada.

Macías Fernández, Daniel. 2019. Franco 'nació en África': los africanistas y las Campañas de Marruecos. Madrid: Tecnos.

Madariaga, María Rosa de. 20o6. Los moros que trajo Franco. Barcelona: RBA.

- 2009. Abd-el-Krim el Jatabi. Madrid: Alianza.

Marín, Manuela; Pérez Alcalde, Juan Ignacio; Puente, Cristina de la, y Fernando Rodríguez Mediano. 2009. Los epistolarios de Julián Ribera Tarragó y Miguel Asín Palacios. Introducción, catálogo e índices. Madrid: Consejo Superior de Investigaciones Científicas.

Mechbal, Adnan. 2011. «Los Moros de la Guerra Civil española: entre memoria e historia».Amnis 2. doi: https://doi.org/10.400o/amnis.1487.

Menéndez Pelayo, Marcelino. 1901. «Prólogo». Dentro Miguel Asín Palacios, Algazel. Dogmática, moral, ascética, 7-39. Zaragoza: Comas Hermanos.

Mesa, José Luis de. 2004. Los moros de la guerra civil española. Madrid: Actas.

Nerín, Gustau. 2005. La guerra que vino de África. Barcelona: Crítica.

Motzkin, Gabriel. 1989. «The Catholic Response to Secularization and the Rise of the History of Science as a Discipline». Science in Context 3: 203-26.

Rein, Raanan. 1999. «In Pursuit of Votes and Economic Treaties: Francoist Spain and the Arab World, 1945-56». Dentro Raanan Rein, ed., Spain and the Mediterranean since 1898, 195-215. London: Frank Cass.

Ribera, Julián. 1893. Discurso leído en la Universidad de Zaragoza en la solemne apertura del curso académico de 1893 a 1894. Zaragoza: Imprenta de Calixto Ariño.

—.1899. «Orígenes de la filosofía de Raimundo Lulio». Dentro varios autores, Homenaje a Menéndez Pelayo en el año vigésimo de su profesorado, 191-216. Madrid: Librería General de Victoriano Suárez.

-1904. «Origen del colegio Nidamí de Bagdad». Dentro varios autores, Homenaje a D. Francisco Codera en su Jubilación del Profesorado. Estudios de Erudición Oriental, 3-17. Zaragoza: Mariano Escar Tipógrafo. 
Ríos Saloma, Martín F. 2011. La Reconquista. Una construcción historiográfica (siglos XVIXIX). Ciudad de México: Universidad Nacional Autónoma de México.

Rivière Gómez, Aurora. 200o. Orientalismo y nacionalismo español. Estudios árabes y hebreos en la Universidad de Madrid (1843-1868). Madrid: Dykinson.

Rodríguez de Cepeda, Rafael. 1897. Organización del Movimiento Científico Católico Contemporáneo. Valencia: Soluciones Católicas.

Velasco de Castro, Rocío. 2014. «La imagen del "moro" en la formulación e instrumentalización del africanismo franquista». Hispania 74 (246): 205-236. doi: https://doi.org/10.3989/hispania.2014.008.

Viguera, María Jesús. 2004. «Estudio introductorio». Dentro Francisco Codera y Zaidín, Decadencia y desaparición de los Almorávides en España. Pamplona: Urgoiti. Wright, Stephanie. 2020. «Glorious Brothers, Unsuitable Lovers: Moroccan Veterans, Spanish Women, and the Mechanisms of Francoist Paternalism». Journal of Contemporary History 55 (1): 52-74. 
